\title{
Ficción e Ideología: La Narrativa Fantástica de Murilo Rubião
}

\section{Universo epigráfico}

Murilo Rubião se caracteriza por el ejercicio riguroso del género fantástico en un momento en que sus contemporáneos actualizan este modo narrativo de manera esporádica, como sucede en las obras de Guimarães Rosa, Aníbal Machado, o en el peculiar contexto maravilloso de Macunaíma, de Mário de Andrade. Pionero de la narrativa fantástica en la literatura brasileña, y autor olvidado por la crítica, renace ahora como objeto de estudio en el medio universitario local.

La más notable de las constantes formales y temáticas en la obra de Murilo Rubião, durante las tres décadas que abarca su producción literaria hasta el momento, es el uso de epígrafes bíblicos que preceden cada uno de sus cuentos . ${ }^{1}$ Ellos se desdoblan en una relación dicotómica epígrafe/cuento (relación intertextual), y epígrafe/epígrafe (relación intratextual).Constituyen una paradoja provocada por la tensión de su propio status, autónomo y dependiente al mismo tiempo, en relación al texto-base (e1 cuento). Los epígrafes sufren entonces una pérdida de funcionalidad al ser extraídos de su texto original, la Biblia, y sufren una consecuente refuncionalización al ser interpolados en un nuevo texto. Existe así una doble función que debe ser observada: por un lado, la carga semántica de su pasado (el texto del cual proviene); por otro, el establecimiento de un nuevo diálogo epígrafe/texto, al ser insertado en un nuevo contexto. Hay un verdadero cruce semántico, encuentro de un pasado textual con un presente narrativo, haciendo del epígrafe una entidad en permanente tensión. Él sintetiza un juego de tiempos: recupera el pasado (su texto original) y se afirma en el presente del nuevo texto, el cual adquiere dimensión de futuridad en la medida en que el epígrafe ocupa siempre un lugar anterior a él. Privilegiado por catalizar tiempos narrativos en diversos niveles, apunta continuamente para su propio pasado, al mismo tiempo que anuncia el texto que le es posterior, haciéndose presente en el acto de su lectura. La tensión de los tiempos se proyecta también en el campo formal: aislado en el blanco de la página, él asume una autonomía aparente, pero en realidad depende 
tanto del texto que le es anterior, cuanto del que le sigue, es en esta dialéctica de convergencias temporales, semánticas y formales que los epígrafes de Murilo Rubião cobran existencia.

Una primera lectura de los mismos, al nivel denotativo, apunta apenas hacia su referente bíblico. Ya una lectura vertical, connotativa, totalizante (esto es, integrados a los textos a los cuales pertenecen), permite trazar una profunda interdependencia en el universo semántico de las dos entidades (epígrafe/cuento).

Los epígrafes que abren cada uno de sus libros ${ }^{2}$ revelan la evolución temática de su obra:

Y cuando yo haya cubierto el cielo de nubes, en ellas aparecerá mi arco-Génesis, IX, 14 (EXM)

Este arco iris, signo de esperanza, plasma sus primeros cuentos. Os Dragões, segunda etapa de su obra, consigna el siguiente epígrafe:

Cosas espantosas y extrañas están sucediendo en la tierra. Jeremías, V, 30.

La perplejidad frente a los acontecimientos es el hilo de tensión que conduce la narrativa en dirección a la radicalización del absurdo de la condición humana, que se observa en cuentos como "A armadilha" y "O edifício". En un tercer momento $(O C)$, el narrador comprueba la aceptación del absurdo de la existencia a través de la mimesis narrativa:

Al sobrevenirles de repente la angustia, ellos buscarán la paz, y nola hallarán - Ezequiel, VII, 25

De este modo, los zoomorfismos, metamorfosis y magias policrómicas que caracterizan la primera etapa de la obra muriliana, quedan ahora dislocados para un segundo plano. No es fortuito el hecho que en el primero y último de los cuentos de $O$ Convidado los epígrafes pertenezcan al libro del Apocalipsis. En esta última fase de su escritura, los epígrafes tienen en común el tono profético que se caracteriza por un momento que será alcanzado:

- "nacerán en sus casas ..." Isaías, XXXIV,13 - "Petúnia"

- "su tiempo está próximo y sus días no se alargarán" Isaías, XIV, 1 -

- "y en aquellos días los hombres buscarán la muerte..."

"O Bloqueio"

Apocalipsis, IX,6 - "Os Comensais"

o un camino que será trillado:

- "yo multiplicaré tus trabajos y tus partos" Génesis,III,16 - "Agláia"

- "ellos te instruirán..." Job, VIII, 10 - “A fila" 
- "yo camino por una vereda, por la cual no volveré"

Job, XVI, 23 - "O convidado"

- "tú abriste camino a tus caballos en el mar" Habacuc, III, 15-

"O lodo"

El "será" está presente en todos ellos, vehiculizado por procesos verbales articulados en el tiempo futuro. Es este el tiempo clave de las profecías. Michel Foucault, en su análisis de la tragedia griega Edipo $R e y^{3}$, muestra que el tiempo profético se realiza en el reconocimiento que el personaje tiene de sus acciones en el pasado, a través de sus diálogos en el presente narrativo. Se trata de un juego de encajes, donde el acontecimiento verbal (futuro) es posteriormente acoplado a un proceso de hechos (pasado histórico de los personajes); hay también una actividad de cuño metalingüístico que avala el tiempo profético.

En Murilo Rubião la profecía no se presenta, como sucede en la tragedia griega, como un desafío oral que exige una revelación posterior a través de las acciones de los personajes. El "encaje" no surge en la relación lenguaje/hecho (o referencialidad), sino en la tensión lenguaje/lenguaje. A partir del momento en que la predicción no depende de determinadas condiciones para su realización, el cuento se reduce a una traducción de su profecía al tiempo presente. En Murilo no hay, entonces, el juego de comprobación de la profecía, ni ésta se concretiza a posteriori, y sí en la duración de la escritura, al nivel del propio lenguaje. El perpetuo acontecer, repetitivo y circular, reduce a un eterno presente el tono pretendidamente futuro de la voz profética. Este pasa a ser entonces máscara del futuro, encubridora de acontecimientos presentes. Es en este juego de encuentros temporales que se instaura el chronos muriliano, y que define la relación estipulada a priori por los epígrafes en cada uno de sus cuentos.

\section{Estructura mitica y el personaje arquetípico}

Los epígrafes seleccionados por Murilo Rubião sorprenden por su nivel profundo de significación: al hilvanar sus primeros epígrafes $(E X M)$ y realizar una lectura acrobática y horizontal de los mismos, surge una narrativa completa e independiente que va a hacer eco en el temario de la obra. ${ }^{4}$ Encontramos así, del punto de vista formal, una narrativa mítica (por su grado de autonomía y universalidad semántica) que incorpora en sí temas que reaparecen en el corpus de sus cuentos, adquiriendo entonces una nítida función metalingüística, ya que los epígrafes remiten constantemente a los textos-base a que pertenecen. De este modo, el tema del héroe epigráfico en su inútil búsqueda ("Y en aquellos días los hombres buscarán la muerte y no la encontrarán; desearán morir, y la muerte huirá de ellos"Apocalipsis, IX,6) se recupera de modo especular en el infructífero trayecto de los dragones por la tierra de los hombres, o en las vanas tentativas del ExMago para huir del tedio y dar sentido a su existencia. La inutilidad de un querer "ser" (y no sólo hacer) aparece de modo altamente metaforizado en las múltiples metamorfosis de Teleco, el conejito: la última y más irónica de 
sus transformaciones, al adquirir finalmente la forma de un niño muerto. El desencuentro con la amada, como manifestación recurrente de la vana búsqueda, es tema central en cuentos como "Elisa" (EXM), donde el movimiento de los dos personajes centrales está conducido de tal modo que el encuentro entre ambos nunca llega a concretarse. La misteriosa llegada de Elisa a la casa del narrador/protagonista se explica apenas como una posibilidad latente de efectivación de una relación que jamás se desarrollará. Este potencial afectivo surge al inicio del relato, en la definición que el narrador hace del personaje central: "Para nosotros era 'ella', simplemente 'ella'. Alguien que precisaba nuestros cuidados, nuestro cariño", pero no llega a concretarse, quedando trabado dentro del individuo. Las acciones de Elisa y del narrador se reducen a tres momentos básicos, que se repiten circularmente, sin consecuencia:

a. llegada de Elisa a la casa del narrador;

b. partida de Elisa;

c. espera del narrador-protagonista por una nueva llegada de Elisa;

a'.nueva llegada de Elisa;

b'. nueva partida de Elisa;

c'. nueva espera del narrador-protagonista por una nueva llegada.

Hay en estas idas y vueltas de Elisa un factor que impide que el apasionado personaje/narrador se le aproxime. Resta una posibilidad continua, pues la espera se convierte en un momento ilusorio que restaura la separación de los personajes. Hay un verdadero movimiento inicial de esperanza, que genera inevitablemente el desencuentro, y que no es más que una nueva proyección del $m \tilde{y}$ thos inicial.

El trayecto del héroe esperanzado es tema central en cuentos como "Alfredo" $(E X M)$, "A cidade" $(E X M)$, "O convidado" $(O C)$, y "A noiva da casa azul" $(E X M)$. En este último cuento el personaje central, motivado por el deseo de encontrar su novia Dalila, llega después de un largo trayecto de tren a la ciudad de Juparassú, para encontrarse con la muerte de ella y con la casa en ruinas. Hay un encuentro con el pasado, donde el artificio del elemento fantástico crea un desencaje temporal en la narrativa, que rompe con las expectativas del personaje central, llevándolo a enfrentar un presente envejecido:

Descolorida y quieta la Casa Azul está delante de mí. Camino entre las ruinas. La escalera de ladrillos cayéndose. La baranda agujereada... Subo penosamente los peldaños de la escalera de ladrillos, podrida. Llego al cuarto de ella: telarañas. ¡Vacío, vacío, Dios mío! Grito: ¡Dalila, Dalila, Dalila! Nada. Corro a los otros cuartos. Todos vacíos, sin muebles. Solo telarañas; las ventanas saliéndose de las paredes.El techo agujereado,el piso podrido.(p.92)

La frustración de la relación ya viene indiciada simbólicamente en el nombre del propio personaje Dalila (traición), y elementos premonitorios 
determinan anticipadamente la esterilidad de tal vínculo: "El padre le había dicho que aquél había sido el noviazgo de la muerte". La infecundidad se proyecta entonces en el tiempo de la narrativa:

... me contó que había sido una epidemia de tifus, que se repitió durante varios años. Motivo por el cual nadie más quiso residir en la región. Los habitantes de la casa de campo que no perecieron, víctimas de la peste, nunca más volvieron... (p. 90)

Así, esterilidad y tiempo andan juntos, y la epidemia de tifus (análoga a la función de las plagas bíblicas), es el elemento maldito que niega la posililidad de continuidad.

El desencuentro y la consecuente búsqueda, surge también como tema central del cuento "Epidolia" $(O C)$, donde las primeras líneas ya son índice de la separación de los personajes: “¿Cómo podría Epidolia haber escapado, si hasta hace algunos instantes la estrechaba contra mi hombro?", y adquiere dimensiones hiperbólicas al final, en una manifestación universal de la inútil búsqueda:

Atrás de él venían los niños, formando un cortejo al cual de inmediato se incorporarían adultos - hombres y mujeres, jóvenes y viejos- unidos todos en un unísono grito: Epidolia, Epidolia, Epidolia. (p. 12)

Este cuento radicaliza la temática del desencuentro, del cual serán víctimas casi todos los personajes de la obra del autor.

La esterilidad de los personajes de Murilo Rubião ${ }^{5}$ se manifiesta de modo más sutil, a través de comentarios del narrador, sin significación en la estructura narrativa, como en el cuento " $O$ edifício" $(O D)$, donde no ocurre ni una tentativa de relación individual por parte del héroe João Gaspar, ya que todo es canalizado hacia lo social. Aun así, el narrador observa: "Al regresar a casa, donde siempre faltaba la diligencia de unos dedos femeninos...". Estas observaciones al margen sirven como llamadas recurrentes del hecho que el hombre nace bajo el signo de la aridez. "Bárbara" $(E X M)$, la más famosa de las heroínas de la obra de Murilo Rubião es un caso peculiar. La exageración de su insaciable voracidad se torna más grandiosa al ser confrontada con la minúscula imagen de su hijo. Ese efecto de contraste (recordemos los recursos iconográficos análogos usados por Chaplin), ya se manifiesta durante el embarazo de Bárbara que "permanecía escondida atrás de la barriga colosal" pero, sorprendentemente, "de aquel vientre descomunal salió un ser raquítico y feo, que pesaba menos de un quilo". El rechazo del niño, a lo largo del cuento, muestra la ausencia de afecto que va a incidir en la atrofia de la relación. Esta variante de la infecundidad asume dimensiones fantásticas en el juego de inversión de proporciones. El rasgo gigantesco del deseo de Bárbara se opone diametralmente al desarrollo del bebé: "El niño tenía que ser llevado en brazos pues, años después de su nacimiento, continuaba del mismo tamaño, sin crecer una pulgada" y este contraste es manifestado por la propia observación del marido: 
A veces miraba a mi hijo, que tal vez nunca llegase a caminar con sus piernitas, y a veces el cuerpo de Bárbara que, de tan gordo, quince hombres, dándose las manos unos a los otros, no conseguirían abrazarlo. (p. 63)

$\mathrm{El}$ exceso (volumen y deseo incomensurables de Bárbara, indiciados metafóricamente por su propio nombre) y la carencia (el minúsculo niño que no crece) se convierten en los extremos de una relación infructífera donde los polos se encuentran; así, el hijo de Bárbara sirve como irónico espejo reductor de su propia imagen.

La negación de la maternidad de Bárbara se proyecta de modo grotesco en la persona de José Inácio en "Memórias do contabilista Pedro Inácio" $(E X M)$. Su nacimiento incide irremediablemente en la muerte de otros; así, cuando José Inácio viene al mundo, su madre muere, y él es dado a otra mujer, sustituyendo el bebé que ella perdiera en un aborto:

Supe esta desagradable revelación el otro día, por casualidad, discutiendo mis teorías sobre herencia con el médico que asistió el verdadero parto de mi madre ficticia. Él me dijo, en un momento en que mis réplicas lo ponían embarazado y nervioso, que yo apenas substituí un aborto.

Como mi verdadera madre no hubiese sobrevivido a mi nacimiento - me explicó el médico - y como era difícil saber, entre los veinte hombres que frecuentaban su casa, cuál sería mi padre, me cambiaron por el feto de mi madre adoptiva. (p. 117)

La paternidad de José Inácio queda diluída delante del número excesivo de posibles padres (veinte), que sumados al binomio filicidio/matricidio, enfatizan la frustración de la relación, así como su carácter sustitutivo.

Así como "Epidolia" condensa la temática del desencuentro, "Agláia" $(O C)$ radicaliza la consecuencia de este momento, que es el de la esterilidad. Pero aquí el tema es desarrollado al revés, a través de la hiperbólica fecundidad del personaje. Paradojalmente, el número desenfrenado de partos de Agláia hace que el nacimiento pierda su significado inicial, reduciendo hechos opuestos a una ecuación de igualdad: fecundidad= esterilidad. La exagerada multiplicación de la especie se opone diametralmente a la interdicción inicial:

....sólo me casaré mediante el compromiso de que no tendremos hijos.

La exigencia era fácil de ser atendida porque la novia tenía idéntico pensamiento. Le repugnaba una prole: pequeña o numerosa...

surgiendo como maldición de la especie humana: la inevitabilidad e irreversibilidad de la existencia y del hecho de nacer. La existencia no significa un acto creativo, sino una estéril repetición: “...los espejos y la cópula son abominables, porque multiplican el número de los hombres", 
afirma Borges en "Tlön, Uqbar, Orbis Tertius". La ausencia de continuidad de vida (impuesta por la interdicción), se iguala a la muerte, en un juego de contiguidad sintáctica y asociación semántica:

...proseguían en el ritual orgiástico hasta la explosión final del sexo.

(El cementerio de vasos y botellas).

(p. 29 - subrayado mío)

donde el orden natural (sexo $=$ vida) sufre una inversión: sexo $=$ muerte (cementerio).

La relación castrada y estéril del héroe arquetípico provoca un proceso de continua sustitución y reificación entre los personajes, como producto de las sucesivas y frustantes tentativas de aproximación entre sí. Estas sustituciones surgen en los más diversos niveles, conduciendo siempre a la paradigmatización de los personajes.

\section{Modernidad de Murilo Rubião}

El concepto de tensión, tan caro a Edgar Allan Poe ${ }^{6}$, generando el efecto hacia el cual todos los elementos del relato deben conducir, aparece diluído en la mayor parte de los cuentos de Murilo Rubião. No encontramos en los cuentos del autor argumentos que produzcan horror, o el clásico 'frisson'; tampoco enredos que conduzcan a la revelación final de la intriga, propio de la narrativa de misterio.

Sirva como ejemplo el cuento "A armadilha" $(O D)$, uno de los pocos cuya articulación es la que más se aproximaría de una narrativa de suspenso; ya el propio título induce a una lectura en ese sentido. Alexandre Saldanha Ribeiro sube por las escaleras de un edificio y encuentra en el décimo piso un viejo que lo espera, apuntándolo con un revólver. La previsibilidad que se crea en el lector durante la lectura sugiere inicialmente un desenlace narrativo en el cual Alexandre sería asesinado, pero pequeños índices empiezan a desintegrar el nexo causal de los acontecimientos. Afirma el viejo: "... esperaba tu llegada. Hace dos años, desde esta silla en que me encuentro, te esperaba seguro que vendrías". Detalles inverosímiles empiezan a romper sutilmente la lógica (temporal, en el caso) del discurso. Así, inversamente a la expectativa del lector ( $y$ del propio personaje), el previsible desenlace no se concreta y el encuentro entre los personajes apunta hacia el infinito. El arma descargada, las ventanas cerradas con tela de alambre, la puerta de acero cerrada, impiden que la 'víctima' vea un fin a la situación, recordando al Ex-Mago en sus vanas tentativas de suicidio.

El trayecto final de Alexandre se convierte así en un camino que va a condenarlo a un encuentro infinito: "Nos quedaremos aquí: un año, diez, cien o mil años". A pesar de que no hay interferencia del elemento sobrenatural, lo cual impide clasificar el discurso como fantástico propiamente dicho, el dato insólito crea un sistema de rupturas de expectativas en el lector. La argumentación obedecería normalmente a la siguiente secuencia: espera $\rightarrow$ encuentro $\rightarrow$ muerte, pero la narrativa es 
bruscamente interrumpida en el segundo momento, extendiéndose ilimitadamente y eliminando la propuesta inicial de venganza por muerte inmediata, sugerida por la presentación del revólver como índice inicial. Se crea así una nueva lógica dentro del discurso, que es la lógica del absurdo.

Otro ejemplo, en este sentido, es el cuento "A lua" $(E V)$, uno de los más perfectos y menos mencionados por la crítica. Este relato también se articula de manera análoga a un cuento de suspenso: el narrador-protagonista (sujeto de la acción), asume el papel de perseguidor-asesino, y el personaje Cris, el de perseguido-asesinado. En ningún momento nos es revelado el motivo de la persecución - tema central del cuento; y el desenlace, que podría suplir elementos reveladores de la intriga, es contaminado por el elemento cósmico:

Sin un gemido y sin el más leve estertor, cayó al suelo. De su cuerpo delgado salió la luna. Una meretriz que pasaba, tal vez impulsada por un impensado gesto, la agarró entre las manos, mientras una garúa de plata cubría las ropas del muerto. La mujer, viendo lo que sostenía entre los dedos, se deshizo en un llanto convulsivo. Abandonando la luna, que fue atravesando lentamente el espacio, ella escondió el rostro en mi hombro. La alejé de mí, y mirando para abajo, contemplé el rostro de Cris. Un rostro de niño. Los ojos azules, la sonrisa de argamasa. (p.21)

Se deshace cualquier propuesta tradicional de lectura de narrativa de suspenso, para dar lugar al indeterminismo sugerido por el propio texto. Este modo narrativo (invariable en la poética del autor), se opone a la teoría de lo fantástico formulada por Tzvetan Todorov, donde el elemento duda es asumido como condición sine qua non para definir el género narrativo en cuestión ${ }^{7}$. Si no surge la duda es porque los elementos ficcionales reales e irreales pactan dentro de su realidad lingüística y temática; consecuentemente la finalidad ya no es despertar determinadas emociones, sino hacer coexistir, a través del artificio verbal, realidades por norma incompatibles, que hacen que el lector sobrepase el nivel ingenuo de la lectura, llevándolo a una visión connotativa del texto. Es así que la sucesión de hiperbólicos pedidos de Bárbara acaban siendo la regla temática narrativa, y no la excepción, permitiéndole al cuento un desenlace coherente con las normas que se fueron estableciendo durante el transcurso de la intriga: "No había pedido la luna. Sino una minúscula estrella, casi invisible a su lado. Fui a buscarla". Nuestra aceptación es análoga a la de la lectura de "Agláia" cuando el narrador comprueba: “...nacieron las primeras hijas con ojos de vidrio..." o cuando, en el desenlace de "A casa do girassol vermelho" $(E X M)$ el personaje-narrador describe:

Levantó los ojos inexpresivos y turbios. Los bajó después para el vientre, donde empezaban a surgir los primeros pétalos de un minúsculo girasol rojo. (p.38) 
Vemos así como el elemento fantástico en Murilo Rubião diluye las relaciones tradicionales del texto con el receptor, instauradas por la clásica narrativa de suspenso, integrando al lector dentro de un universo basado en un absurdo verosímil. Es esta ausencia de perplejidad frente al hecho sobrenatural que hace que la narrativa del autor esté cargada de modernidad, uniéndola, a partir del ejemplo de Kafka, a una constelación de escritores latinoamericanos: Mário de Andrade, Jorge Luis Borges, Julio Cortázar, Juan Rulfo, Gabriel García Márquez, José Donoso y, dislocado en su tiempo, Machado de Assis.

Esta cotidianeidad de lo fantástico permite al lector un distanciamiento en relación al texto y, consecuentemente, una postura crítica. Es un proceso análogo al verfremdung brechtiano que, al disminuir la identificación empático/catártica (aristotélica) del espectador en relación a la obra, aumenta su capacidad analítico-crítica. No en vano cuentos como "La metamorfosis"de Kafka, "El guardagujas" de Juan José Arreola, "A cidade" de Murilo Rubião u obras consagradas como Memórias Póstumas de Brás Cubas o Cien años de soledad de G.G.Márquez, enmascaran agudas críticas sociales, sin limitar el texto a una mera experiencia de fruición de lectura.

\section{Ideología de lo fantástico}

La poeticidad de la obradeMurilo Rubião contiene su plurisignificación: así, el lenguaje connotativo de la narrativa genera textos posibles de ser descodificados en una lectura ideológica, reveladora de presencias culturales latentes. De este modo, el lenguaje de lo fantástico adquiere funciones que se proyectan más allá del texto ficcional, para vincularse a series culturales de orden universal.

\subsection{El texto cristiano}

El primero de estos contextos culturales es el texto cristiano que se evidencia explícita e implícitamente en la obra del autor. Así, los epígrafes bíblicos que preceden todos los cuentos, constituyen alertas constantes de un pensamiento, al nivel más denotativo de la expresión. Pero la presencia evidente de fragmentos de la Biblia no es el único elemento que justifica la existencia de un cruce textual con la poética de Murilo Rubião, cuya narrativa aparece filtrada por el pensamiento cristiano.

Sirva como ejemplo el cuento "Botão-de-Rosa" $(O C)$, que gira en torno al juicio del personaje central (que lleva el nombre del cuento), por haber embarazado todas las mujeres de la ciudad, y que remite a la figura de Cristo a través de sus acciones y atributos. La apariencia física constituye el primer índice caracterizador de esta analogía: "largos cabellos", "túnica blanca", "sandalias", etc. Sus "compañeros del conjunto de guitarras" son exactamente doce, simbolizando los apóstoles. Más aún, Botão-de-Rosa es traicionado por uno de ellos (recuperando así la tradición de la figura de Judas), y su comportamiento obedece al más elevado de los estoicismos ("un pobre diablo que se negaba a defenderse y ni se importaba con su propia 
condena"), mientras su muerte cataliza los pecados del hombre (en el caso, irónicamente descritos en el embarazo de las mujeres), y su pureza, referencializada a través del propio nombre, se manifiesta simbólicamente por su desprendimiento total en el momento de su muerte: “...desnudo, ofreció el cuello al verdugo".

La superposición textual que el cuento sugiere en relación al relato bíblico permite categorizarlo como parodia alegórica. Es el caso de "O edifício", que remite en su globalidad y transparencia de lectura al mito de la Torre de Babel.

\subsection{El texto social}

El simbolismo del lenguaje en Murilo Rubião se presenta al lector como un sistema poroso que filtra constantemente los elementos sociales del texto. Son raros los momentos en la obra del autor en que el elemento insólito, o aún el sobrenatural, no se convierta en trampolín metafórico de una crítica social. Lo fantástico como transfiguración lúdica de la realidad es escaso en los cuentos, y la posibilidad de connotación social enriquece el signo narrativo, permitiendo que se proyecte más allá del fenómeno meramente ficcional. El elemento social es vehiculizado por la imaginería fantástica, mimesis inverosímil del universo: "la creación literaria corresponde a ciertas necesidades de representación de mundo, a veces como preámbulo a una praxis socialmente condicionada. Pero esto sólo se torna posible gracias a una reducción a lo gratuito, a lo teóricamente incondicionado, que da ingreso al mundo de la ilusión y se transforma dialécticamente en algo empeñado, en la medida en que suscita una visión de mundo", afirma Antonio Candido ${ }^{8}$. Así, la máscara justifica, en la fuerza de su representación, aquello que da sentido a su existencia: el elemento enmascarado.

La burocracia, como sistema formal repetitivo conductor del absurdo por el vaciamiento del significado, es objeto de algunos cuentos del autor. Es en este momento que la herencia kafkiana es notable, en la figuración de un universo donde el hombre pierde su individualidad frente a la masacrante fuerza coercitiva que implica el aparato burocrático. Así, la afirmación que inaugura la obra de Murilo Rubião: "Hoy soy un funcionario público", tiene repercusiones en el resto de su narrativa. La crítica a la burocracia aparece en el cuento "OEx-Mágico da taberna minhota" $(E X M)$ de modo explícito: "No estaba más en condiciones de determinar cual era la forma de suicidio que me convenía mejor - si lenta o rápida. Por eso, me empleé en una Secretaría del Estado", afirma el Ex-Mago. La ironía adquiere dimensiones trágicas, pues el ingreso en la burocracia aniquila su poder creativo, siéndole revelado, a través de su semejante, el espanto de la realidad: "Ahora que vivía en constante contacto con mis semejantes, precisaba comprenderlos, disfrazar el horror que sentía, contemplando sus rostros". Es así que él iguala la vida al suicidio, pasando a cargar la etiqueta que revela una existencia pasada: $E x$-Mago. De este modo, el héroe se presenta al lector como el fracaso de una posibilidad. 
El tema de la burocracia se formaliza en el cuento "A fila" $(O C)$, donde la dimensión hiperbólica que ésta adquiere en el transcurso del relato es mimetizado por el propio acto de la narración: la fila crece, el cuento crece. Y la vuelta incesante del personaje para ocupar, en la fila, un lugar cada vez más alejado, se formaliza en la propia redundancia semántica del discurso, haciendo de la repetición y la hipérbole los recursos retóricos por excelencia. Un caso extremo se da en el cuento "O edifício", que propone un lenguaje burocrático adecuado al tema propuesto (la propia división del cuento en 10 partes ya es un índice de burocratización), donde las leyes se convierten en el personaje central que rige el universo humano de un absurdo propósito. De este modo, forma y contenido imbricados, hacen de la significación un puente con lo real.

\subsection{El texto existencialista}

Lo fantástico en Murilo Rubião no se restringe, dentro de sus posibilidades connotativas, a la crítica a un sistema social. El hecho de que los personajes no se configuren como individuos dotados de un mundo interior denso no implica que esta narrativa no vea al hombre en su individualidad. Así, el cuestionamiento del "hombre-y-su-circunstancia" es uno de los subtextos al cual remite el lenguaje de lo fantástico. Si en "O edifício", el contexto sirve para subordinar al hombre a sus leyes perennes, en "O bloqueio" $(O C)$ el desmontaje progresivo y regresivo del edificio converge para el individuo en un proceso reductivo que tiende a llegar a su esencia.

El refectorio, local donde el individuo se establece como ocupante extraño de un recinto, es tema que aparece en gran número de cuentos del autor:

Desde una fecha que no podría precisar, todos los días, a la hora del almuerzo y de la cena, ella se sentaba delante de mí, a la mesa, donde por quince años fuí el único e invariable ocupante.

"Os três nomes de Godofredo" (EXM,p.143)

Es en el comedor de "Os comensais" que el contexto surge plasmado por la exacerbación de la individualidad, en el sentido existencialista de Camus (cf.El Mito de Sísifo) de la desarticulación que el hombre siente en relación a su mundo circundante. Así, Jadon, héroe del cuento, intenta en vano relacionarse "para romper la opresiva indiferencia de los comensales", petrificados en sus propias individualidades. Su capitulación frente al contexto se cristaliza en el comentario final del narrador: "Estaba solo en la sala inmensa".

Cuando el personaje no se encuentra dentro del recinto, la intriga incluye el trayecto que a éste lleva. Así, el héroe de "A noiva da casa azul" es el pasajerode un tren en dirección a Juparassú, así como el personaje central de "A cidade" es el único pasajero del tren que lo conduce por un trayecto irreversible: "...camino por una vereda por la cual no volvere", afirma el epígrafe de "O convidado", espejando el trayecto de José Alferes en relación 
a la enigmática fiesta. El ambiente, como contexto del cual el hombre es prisionero, está presente en "Os comensais" en el comentario del narrador:"Jadon perseveraba en su inútil tentativa de huir de aquel recinto". (La intertextualidad con temas buñuelescos es evidente, en los comedores de "El ángel exterminador", "El discreto encanto de la burguesía", o la absurda escena comedor/w.c. de "El fantasma de la libertad"). Análogamente, la víctima de "A armadilha" llega al final del edificio para nunca más salir de él. Edificios, comedores, trenes, reparticiones, nada más son que metáforas arquitectónicas de la estructura social en la cual el individuo está condenado a permanecer. Del mismo modo la entrada y salida de los dragones de la ciudad ("Os dragóes ") que, en paradigma con los personajes/contexto anteriores, vehiculizan la condición absurda del "estar-en-el-mundo" del hombre. Incomunicabilidad y soledad, como consecuencias inevitables de la existencia del hombre decurrentes de su presencia en el mundo, son los elementos que acompañan, sin excepción, los personajes del universo muriliano.

La poeticidad de lo fantástico en Murilo Rubião no se limita apenas a la existencia lingǘstica de lo inverosímil, sino que reside en la densidad del signo, por la posibilidad múltiple de descodificación. La amálgama de tres sub-textos: el cristiano, el social y el existencial urden la trama consistente de una narrativa que se universaliza en la posibilidad de establecer homologías con el contexto, en última instancia, el hombre. Y en la relación texto/contexto, la obra de arte sintetiza, en su inmanencia, plausibles universos culturales.

Universidade de São Paulo

JORGE SCHWARTZ

NOTAS

$1 \mathrm{El}$ aspecto unitario de la obra de Murilo Rubião, así como su relación con los epígrafes, fue apuntado por Eliane Zagury. Afirma la crítica en su análisis pionero de Os Dragões e outros contos: "La unidad de la obra de Murilo Rubião es indiscutible. Tanto asi que ha sido posible englobarla bajo un epígrafe: Cosas espantosas y extrañas están sucediendo en la tierra. Jeremías, V, 30" en Cadernos Brasileiros no. 36 - julho/agosto 1966 - ano VIII, no 4, Rio de Janeiro, pp. $81-85$.

2 Para efectos de cita, emplearemos las siguientes abreviaturas: $E X M(O E x-M a ́ g i c o, 1947)$; EV (A Estrela Vermelha, 1953); OD (Os Dragzes e Outros Contos, 1965); OC (O Convidado, 1974).

3 Foucault, Michel - "A verdade e as formas juridicas" en Cadernos da PUC-RJ, Série Letras e Artes 06/74. Caderno no. 16, Rio de Janeiro, 1974.

4 Los treinta y cinco epígrafes que componen la totalidad de sus cuentos hasta el momento, fueron objeto de estudio en el primer capítulo de mi libro, Murilo Rubião: a poética do uroboro que la Editora Ática publicará próximamente en São Paulo.

5 La esterilidad, como tema central en la obra de Murilo Rubião, fue apuntada por Davi Arrigucci Jr. en su prefacio " $O$ mágico desencantado ou as metamorfoses de Murilo", en $O$ Pirotécnico Zacarias, Atica, São Paulo, 1975. 
6 Poe, E.A. - "Nathaniel Hawthorne" en Tales, Poems, Essays, Collins, London, 1952, p.521. Véase tambien "The Philosophy of Composition".

7 Todorov, Tzvetan - Introduction a la littérature fantastique, Seuil, Paris, 1970. Para una crítica minuciosa al trabajo de T. Todorov, consultar Jean Bellemin Noel, "Des formes fantastiques aux thèmes fantasmatiques", en Littérature no. 2, 1971. Texto fundamental, para el género en cuestión, es la obra de Irène Bessière, Le récit fantastique, Larousse, Paris, 1974, que incluye una crítica aguda a la obra del autor: "Todorov et linexact partage du fantastique",pp. 54-59.

8 Candido, Antonio - Literatura e Sociedade, Companhia Editora Nacional,3a.ed., 1973(1a. ed. 1965), p.55. 
